\title{
A REVIEW OF THE SUBSPECIES CONCEPT \\ IN THE EUMENINE GENUS ZETA \\ (HYMENOPTERA: VESPIDAE)*
}

\author{
By JAMes M. CARPENTER \\ Museum of Comparative Zoology, Harvard University, \\ Cambridge, MA 02138
}

Menke and Stange (1986) reported the establishment of the potter wasp Zeta argillaceum argillaceum (L.) in Dade County, Florida. This is the first species of this neotropical genus to be found in the United States. While identifying a small collection of Florida eumenines for Dr. Peter J. Landolt of the USDA Insect Attractants Lab in Gainesville, I discovered an additional specimen of this species from Dade County. It represents a color form, or "subspecies", different from that reported by Menke and Stange (1986). In this note I discuss recognition of subspecies in Zeta, and demonstrate that most are artificial taxa. Plasticity in coloration is a common phenomenon in Hymenoptera, and has even been shown to be experimentally manipulable in Vespidae (MacLean et al., 1978). Yet recognition of subspecies purely on the basis of color differences remains a common practice in vespids, including Zeta, and other aculeates. The recent revision of the genus by Giordani Soika (1975) recognizes only four species in Zeta, but these are divided into no fewer than 15 subspecies, 10 of which are in argillaceum! These are all based on color, and in the continental forms the distributions frequently overlap. I have examined most of these "subspecies", and conclude that they do not merit formal recognition. Most of them are synonymized below. I have not treated the subspecies of the Antillean abdominale. Acronyms for collections are those of Heppner and Lamas (1982).

\section{Zeta argillaceum (L.)}

Sphex argillacea Linnaeus, 1758: 569. (type $\$$ BMNH)_-"Surinami."

Vespa canaliculata Olivier, 1792: 672. Type depository unknown-"Cayenne." Vespa diadema Fabricius, 1798: 263. (ZMUC)_-Cajennae."

*Manuscript received by the editor June 3, 1987 
Eumenes orbignii Saussure, 1852: 69. \& (MNHP)_-Bolivie, Chiquitos." NEW STATUS.

Eumenes orbignyi (!) Saussure, 1853, Table alphabétique: 273.

Eumenes canaliculatus var. dives Zavattari, 1912: 129. \& (lectotype NHMV, designated by Giordani Soika, 1975: 122)_-“Ecuador: Guayaquil.” NEW STATUS.

Eumenes lineatifrons Cameron, 1912: 227. ㅇ (BMNH).

Zeteumenes canaliculata for. riojana Bertoni, 1934: 110. Type probably lost-“La Rioja." NEW STATUS.

Zeteumenes argillaceus hubrichi Giordani Soika, 1969: 383. ㅇํ ổ (type $q$ Zool. Staatsammlung, Monaco) - “Argentina: Granja.” NEW STATUS.

Zeta argillaceum incarum Giordani Soika, 1975: 116, 126. 우 $\hat{\sigma}$ (type $q$ USNM) - "Peru: Valle Chanchamayo, $800 \mathrm{~m}$." NEW STATUS.

Zeta argillaceum distinguendum Giordani Soika, 1975: 117, 124. ㅇ fô (type $\widehat{\sigma}$ Zool. Staatsammlung, Monaco)-“Argentina: Buenos Aires, Tandil.” NEW STATUS.

Zeta argillaceum apurimacense Giordani Soika, 1975: 117, 125. 우 $\hat{\sigma}$ (type $\hat{\sigma}$ BMNH)_-“Peru: Apurimac, Cuzco-Abacay Road, Apurimac Crossing at Cuya, 1900 m." NEW STATUS.

Zeta argillaceum pallidior Giordani Soika, 1975: 117, 127. $\&$ ô (type $q$ stated to be at CU, but not found)_-"Messico: 3 miglia a N di Alpuyeka, $3440 \mathrm{ft} . " N E W$ STATUS.

Zeta argillaceum peruense Giordani Soika, 1975: 118, 126. 우 ô (peruensis; type 우 BMNH). NEW STATUS.

A male collected at the USDA Lab in Dade Co., Florida on Nov. 6, 1981 by Dr. Landolt and now in the MCZ most closely resembles hubrichi, originally described from Argentina. The specimen is primarily reddish brown with limited yellow maculations as follows: the pronotum rimmed both anteriorly and posteriorly, the mesepisternum in part, a line in front of the parategula, and the scutellum laterally and metanotum entirely. The second metasomal tergum is not darker than the successive terga. However, this pattern is either developed or approached in specimens determined as other subspecies in the collections of the MCZ (most of the specimens listed in Giordani Soika, 1975, as being in the USNM are in fact in the MCZ, and there are numerous other similar errors), CU and USNM. Careful examination of series of these subspecies showed discrepancies with Giordani Soika's (1975) key, as well as transitional forms and distributional overlap. I have seen specimens of nine of the ten subspecies of argillaceum in the collections of the MCZ, CU and USNM, and cannot consider them distinct. The following discussion documents the synonymy.

The difficulties begin with the first couplet of Giordani Soika's subspecies key, which gives as alternatives (my translation): 
"Ferruginous, or brown-ferruginous, and black without yellow markings. In some examples (transitional to hubrichi) part of the posterior margin of the pronotum and apex of tergum I may be yellow."

vs.

"Yellow markings fairly extensive both on thorax and abdomen." This vague couplet fails for numerous specimens in the MCZ from Brazil, Nova Teutonia, determined by Giordani Soika as orbignii, as well as other specimens from Paraguay and Argentina. This subspecies is supposed to key to the first alternative, but may have the yellow markings as extensive as in hubrichi or distinguendum, which are supposed to key to the second alternative. But examination of these specimens further shows that the distinction between the typical subspecies and orbignii does not hold up. The typical form is distinguished from orbignii only by having the second tergum darker than successive terga and the mesosoma. Typical argillaceum is confined to the Guianas, while orbignii is listed in Giordani Soika (1975) as occurring in Trinidad, Brazil, Bolivia, Peru, Paraguay, Uruguay and Argentina-although he himself (pp. 116 and 119) noted transitional forms in Brazil, Paraguay and Argentina. The specimens in the MCZ, CU and USNM show great variation in the darkness of tergum II throughout the range of orbignii. There are specimens assignable to the typical subspecies from Trinidad, Brazil, Peru, Paraguay and Argentina (as well as Venezuela and Colombia). Recognition of orbignii as a subspecies separate from the typical form is therefore unwarranted. The specimens cited by Giordani Soika as transitional to hubrichi also belong here. Two specimens labelled as such by Giordani Soika are in the collections of CU and the USNM, and they have the terga dark. One other "subspecies" keys to the first alternative of the first couplet, and belongs here. This is incarum Giordani Soika, described from the Cordillera in Peru. I have seen two specimens from CU. It is the only subspecies distinguished in the key by a morphological feature, namely the relative length of the hair on the scutum. However, this also occurs in the subspecies peruense, as well as numerous other species of eumenines found at higher elevations throughout the world. It seems to be primarily an ecological correlate. There is no other difference-the metasomal terga are black or brown, as in typical argillaceum. 
The remaining seven subspecies are supposed to key to the second alternative. They are not really distinct from one another. The character distinguishing dives and riojanum in Giordani Soika's key, whether the pronotum is entirely or only partly yellow, is both trivial and not really true. For example, one of the MCZ specimens of riojanum from Belen-Los Nacimentos (seen by Giordani Soika, but cited as deposited in the USNM), and three CU and one USNM specimens from La Rioja have the pronotum nearly entirely yellow - supposed to characterize dives. The subspecies peruense in turn differs from these two forms in the amount of black on the mesepisternum and pronotum, as well as the relatively long hair on the scutum. These are all trivial features; the color in peruense differs only in having the black sometimes more extensive on the pronotum and mesepisternum, but there are specimens in the USNM with the pronotum completely yellow, and the amount of black on the mesepisternum varies considerably in specimens of all three subspecies. The length of the hair is probably an ecological correlate, as noted above. The characters cited in the key as distinguishing hubrichi from the three preceding subspecies all occur in dives and riojanum. The subspecies pallidior is in turn distinguished from these four forms by reduction of the black markings; it is Mexican while the others are South American. A specimen in the MCZ from Costa Rica: Guanacaste Prov., Playa Brasilito has the black markings limited to the base of terga I and II, the base of the metapleuron and the scutum. A specimen at CU from Panama, Coco Solo CZ is similar, but has a mesal black line on the scutum and most of the metapleura black. These specimens are thus intermediate both in color and range. The subspecies distinguendum is distinguished from these five forms only by having the propodeum black, whereas it is primarily yellow or ferruginous in the other subspecies. However black markings may appear in specimens of these other subspecies, and their extent varies in specimens of dives from Peru and Ecuador in the USNM. Recognition of any of these six forms as subspecies is therefore unjustified. Further, although I have not seen specimens of apurimacense, the characteristics by which it is distinguished from distinguendum in the key are subject to the same kind of variation as those just discussed. These are the extent of yellow on the dorsum of the thorax and ferruginous on the first metasomal tergum. I am confident that apurimacense is no more than another minor local variant, and have no hesitation in synonymizing it. 
Finally, as mentioned above the initial couplet as written fails to separate the subspecies into two distinct groups, but can a distinction be made? Specimens supposed to key to the first alternative are typically darker than those supposed to key to the second alternative: the metasomal terga are usually black or brown in the first group and light reddish in the second; the yellow markings are usually much more extensive in the latter. The darker form is distributed from the Guianas south to Argentina, primarily east of the Cordillera, whereas the lighter form is distributed along the Cordillera north to Central America. But these forms overlap in northwestern Argentina (cf. Giordani Soika, 1975), Paraguay (MCZ specimens from Mborero and Molino-cué), Peru, Colombia (an MCZ specimen of "typical argillaceum" is from Meta: Carimagua) and Venezuela (MCZ and USNM specimens). Nor are they always distinct in color. Variation in the extent of yellow was already discussed, and the darkness of the metasoma is also uncorrelated with distribution. For example, specimens of distinguendum I have examined have the metasoma as black as dark specimens of orbignii, while pale specimens of the latter have the metasoma light reddish. So even just these two groups cannot really be diagnosed. Recognition of subspecies is in my view a poor way of dealing with color variation in vespids anyway, but in this species it is untenable.

\section{Zeta confusum (Bequaert \& Salt)}

Eumenes confusus Bequaert \& Salt, 1931: 768. 우 (type 오 MCZ)- "CUBA. Soledad". The following label data were not mentioned in the description: collected by Geo. Salt, March 28, 1925, at Spodeas purpurea.

Eumenes confusus var. pinetorum Bequaert \& Salt, 1931: 771. 우 (type $\$$ CMP)_-“Nueva Gerona, ISLE OF PINES (G. Link)”. NEW STATUS.

The subspecies in confusum are at least allopatric, but examination of the material in the collection of the MCZ confirms that these subspecies are not really distinct. The subspecies pinetorum was distinguished from the typical form by reduced yellow markings on the mesosoma and the metasoma being "ferruginous" red, as opposed to orange red. I have examined the holotype of the typical form, ten paratypes (these latter specimens were not labelled as such, but the locality data correspond to those listed in the original description), and the two paratypes of pinetorum mentioned by Bequaert and Salt (1931) as deposited in the MCZ (and listed by Giordani Soika as deposited in the USNM). I have seen 13 additional specimens pinned in the same unit tray as typical confusum, 
from various localities in Cuba: Havana, San Blas, Baraguá and simply "Cuba" or no locality (some also seen by Giordani Soika). However, one is from the Isle of Pines, and so assignable to pinetorum. These specimens show extensive variation in the extent of yellow on the mesosoma and the color of the metasoma, so that the color distinction does not hold up here either. Since pinetorum is thus not "a distinct color form" (Bequaert and Salt, 1931), I synonymize it with the typical form.

\section{SUMMARY}

Subspecies concepts in the eumenine genus Zeta are discussed. Examination of subspecies in the genus distinguished by color alone indicates that the distinctions between them do not hold up, and the following are synonymized: orbignii (Saussure), dives (Zavattari), riojanum (Bertoni), hubrichi (Giordani Soika), incarum Giordani Soika, distinguendum Giordani Soika, apurimacense Giordani Soika, pallidior Giordani Soika and peruense Giordani Soika with typical argillaceum (L.); pinetorum (Bequaert \& Salt) with confusum (Bequaert \& Salt).

\section{ACKNOWLEDGMENTS}

I thank Peter J. Landolt for sending the Florida specimen which occasioned this work. J. K. Liebherr made the specimens of Cornell University available for study. Arnold S. Menke arranged the loan of material from the U.S. National Museum, and made valuable comments on the manuscript. This research has been supported by NSF Grant BSR-8508055 to the author.

\section{Literature Cited}

Bequaert, J. and G. Salt

1931. New West Indian Diploptera. Ann. Entomol. Soc. Amer. 24: 765-797. Bertoni, A. W.

1934. Contribución al conocimiento de los eumeneidos. El antiguo genero Eumenes Latr. (s. lat.). (Nuevo punto de vista para la clasificación). Rev. Soc. Cient. Paraguay 3: 109-122.

Cameron, $\mathbf{P}$.

1912. The Hymenoptera of the Georgetown Museum. Part III. The Marabuntas or wasps. Timehri J. R. Agric. Commerc. Soc. Brit. Guiana 2: 207-231. 
FABRICIUS, J. C. F.

1798. Supplementum Entomologiae Systematicae. Hafniae.

GIORDANi SoIKA, A.

1969. Nuovi eumenidi della regione neotropicale. (Notulae vespidologicae XXVII). Mem. Soc. Entomol. Ital. 48: 379-384.

1975. Sul genere Zeta (Sauss.). Boll. Mus. Civ. Stor. Nat. Venezia 27: 111-135. HEPPNER, J. B. AND G. LAMAS

1982. Acronyms for world museum collections of insects, with an emphasis on neotropical Lepidoptera. Bull. Entomol. Soc. Amer. 28: 305-315.

LinNaEus, $\mathrm{C}$.

1758. Systema Naturae, I. (10th ed.). Laurentii Salvii, Holmiae.

Maclean, B. K., L. Chandler and D. B. Maclean.

1978. Phenotypic expression in the paper wasp Polistes fuscatus (Hymenoptera: Vespidae). Great Lakes Ent. 11: 105-116.

Menke, A. S. and L. A. Stange

1986. Delta campaniforme rendalli (Bingham) and Zeta argillaceum argillaceum (Linnaeus) established in southern Florida, and comments on generic discretion in Eumenes s. l. (Hymenoptera: Vespidae; Eumeninae). Fla. Ent. 69: 697-702.

Olivier, A. G.

1791-1792. Encyclopédie Méthodique, 6(2), pp. 1-368 (1791); pp. 369-709 (1792). Paris.

SAUSSURE, H. F. DE

1852-1853. Etudes sur la Famille des Vespides, Vol. I, pp. i-128 (1852); pp. 129-286 (1853). Masson, Paris, and J. Cherbuliez, Geneva.

ZAVATTARI, E.

1912. Materialien für eine Monographie der Neotropischen Eumeniden. Arch. Naturgesch. 78A: 1-272. 

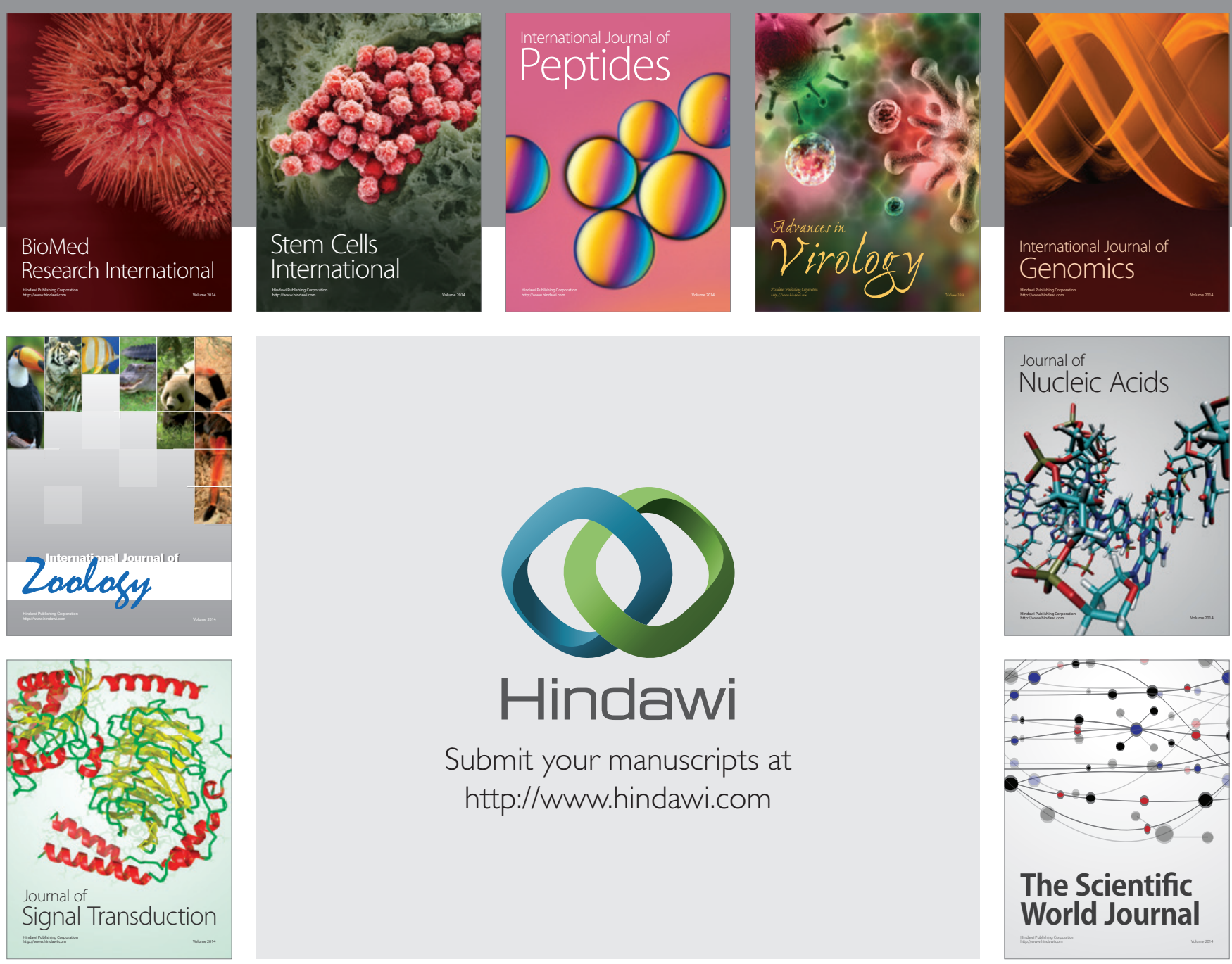

Submit your manuscripts at

http://www.hindawi.com
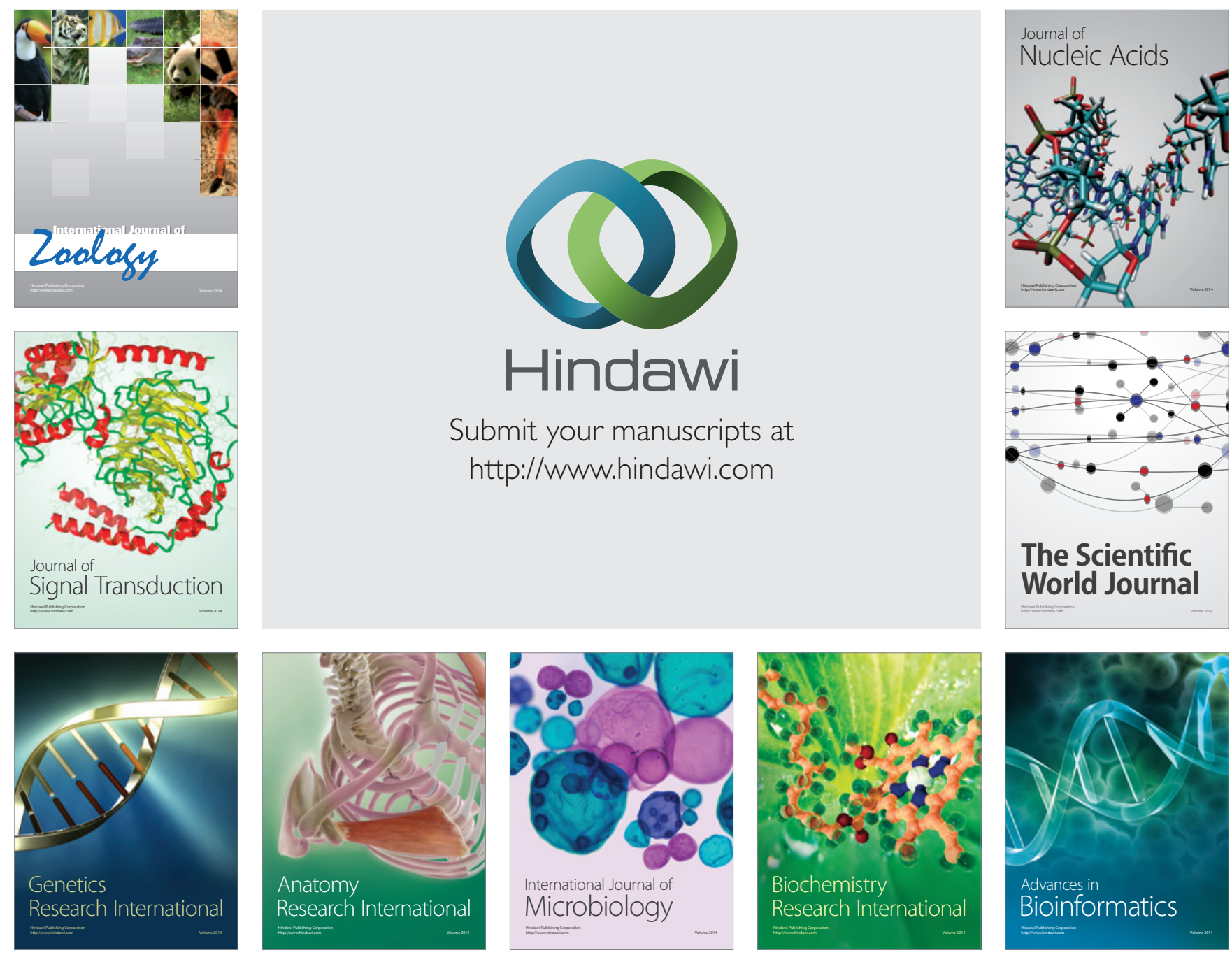

The Scientific World Journal
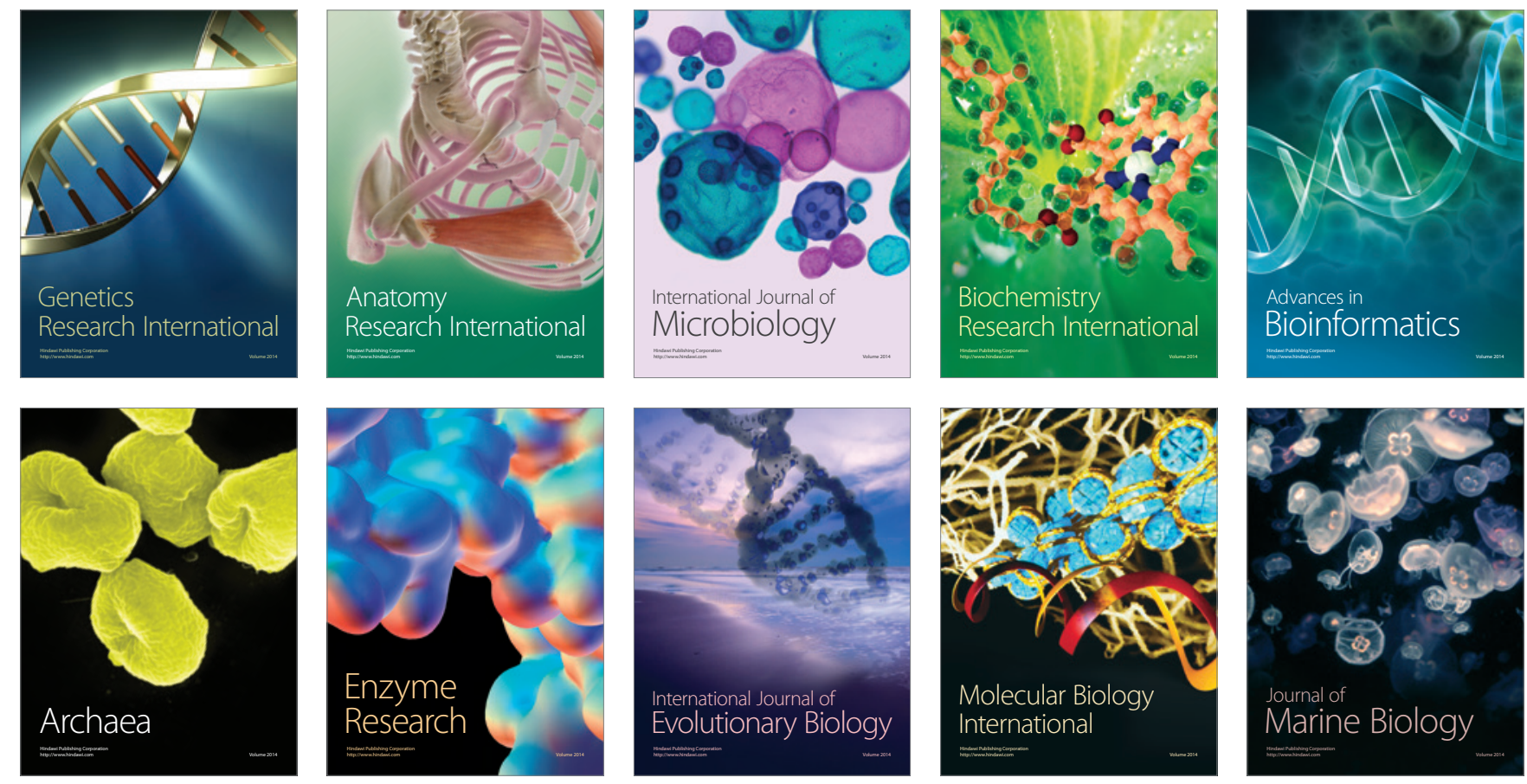